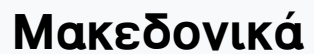

Tóp. 4, Ap. 1 (1960)

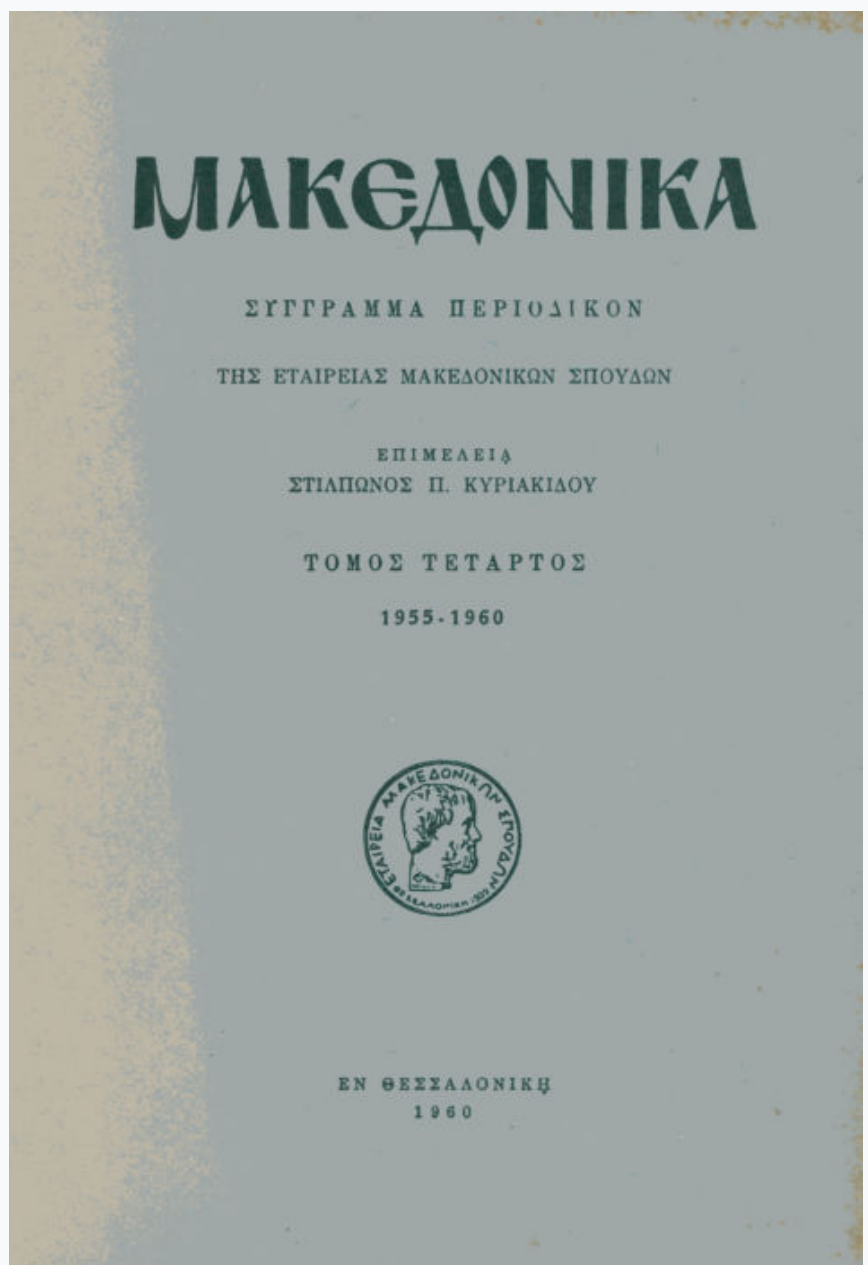

\section{André Guillou, Les archives de Saint-Jean- Prodrome sur le mont Menécée}

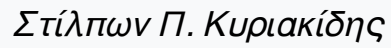

doi: 10.12681/makedonika.771

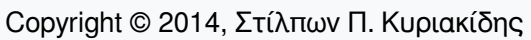

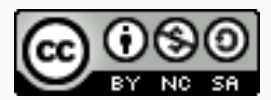

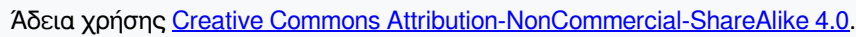

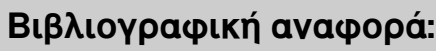

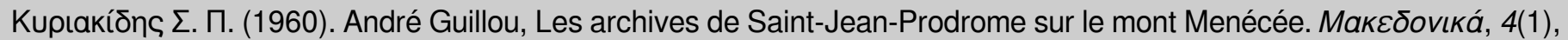
610-614. https://doi.org/10.12681/makedonika.771 


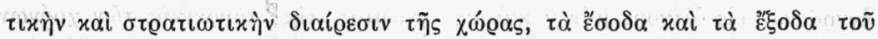

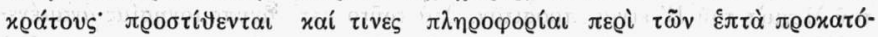

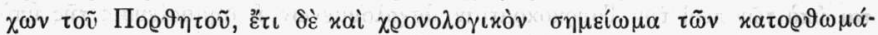

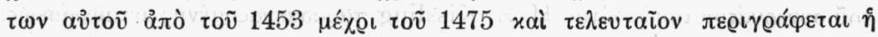

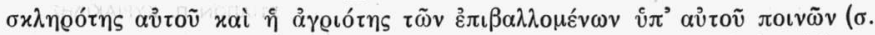
89). "Diuerse sono, $\lambda \hat{\varepsilon} \gamma \varepsilon ı$, immo horribile le iustitie et iniustitie et

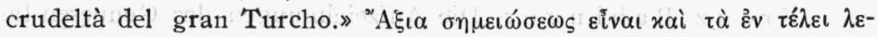

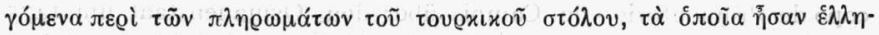

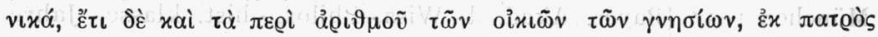

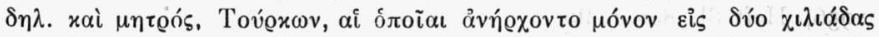

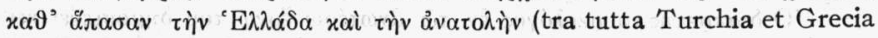

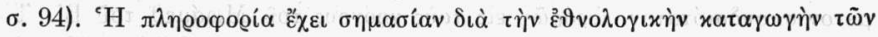

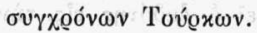

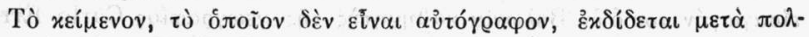

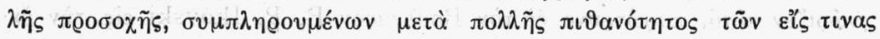

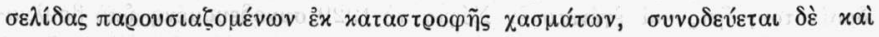

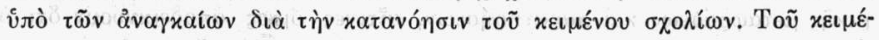

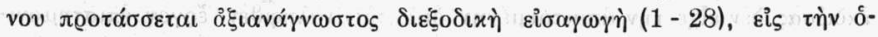

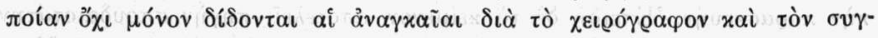

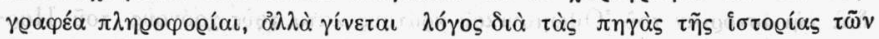

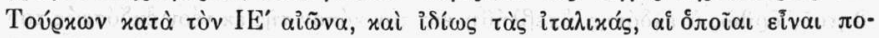

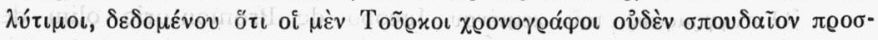

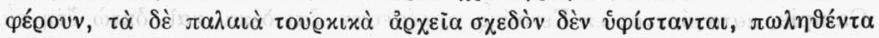

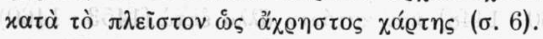

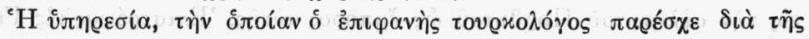

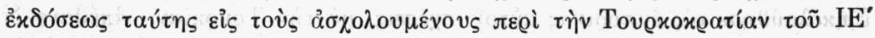

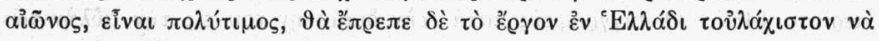

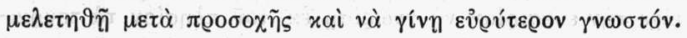

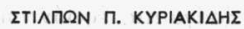

André Guillou, Les archives de Saint-Jean.Prodrome sur le mont Menécée. Paris 1955 (Bibliothéque byrantine publiée sous

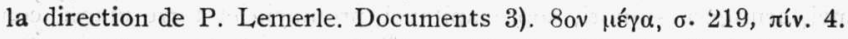

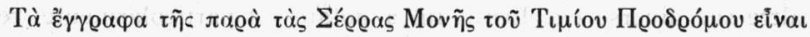

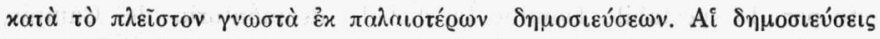

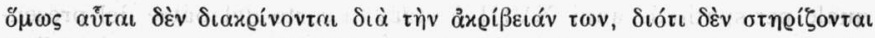

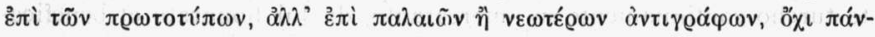

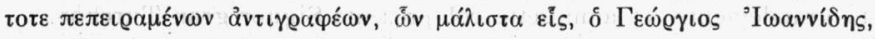

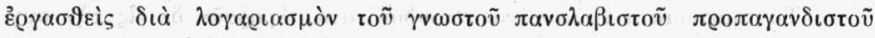

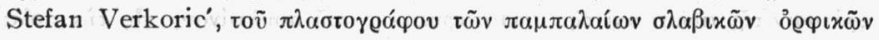




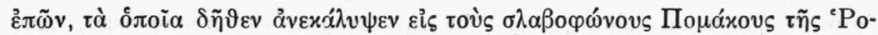

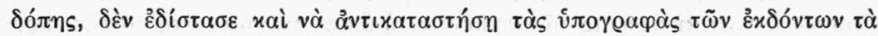

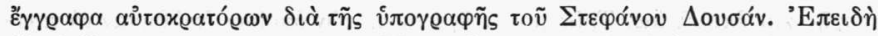

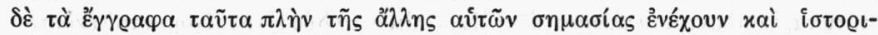

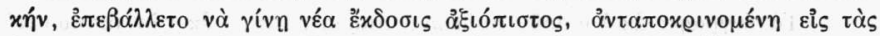

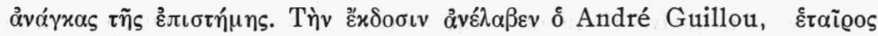

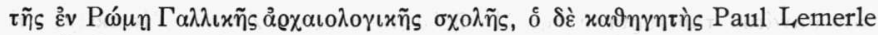

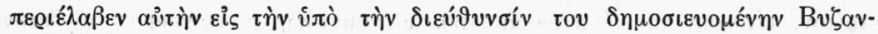

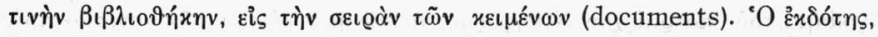

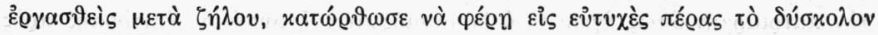

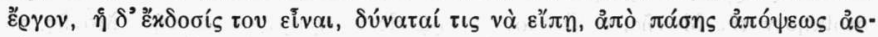

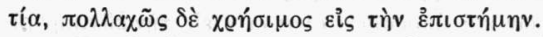

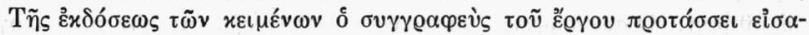

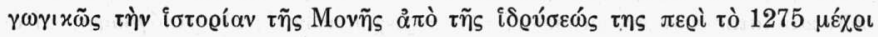

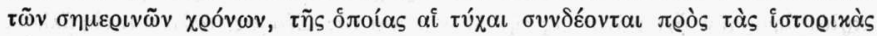

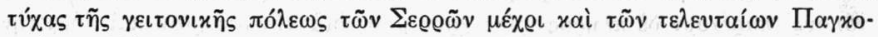

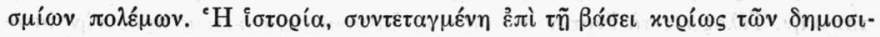

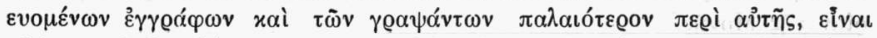

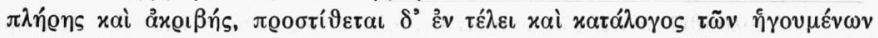

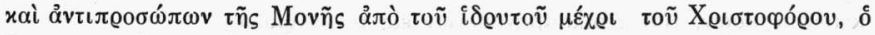

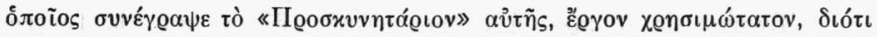

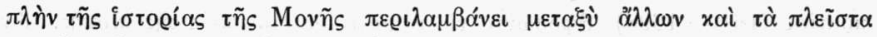

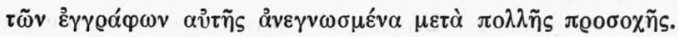

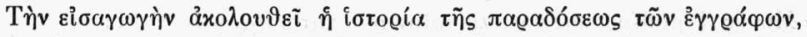

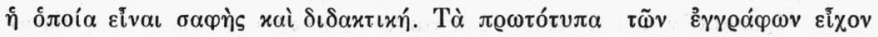

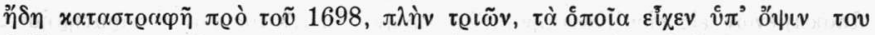

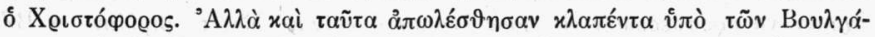

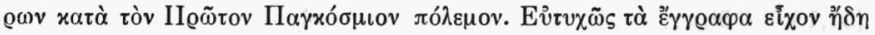

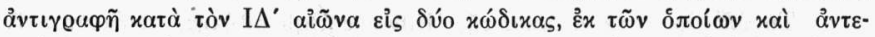

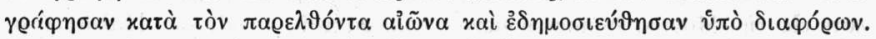

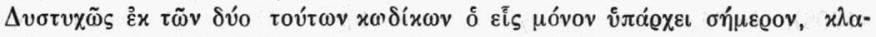

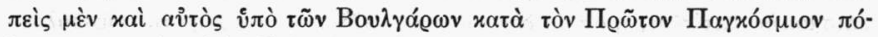

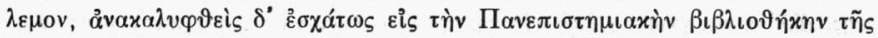

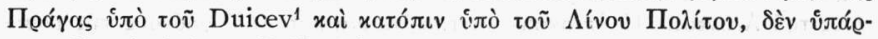

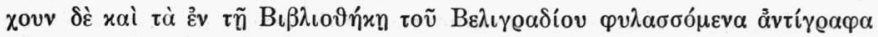

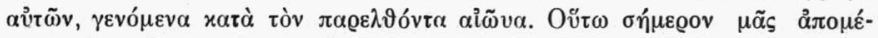

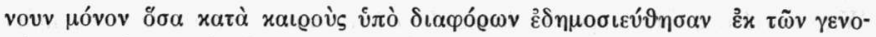

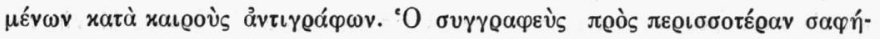




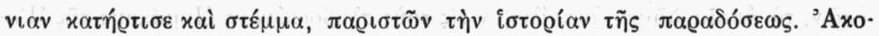
$\lambda \circ v \vartheta \varepsilon \tilde{~}$ ท์

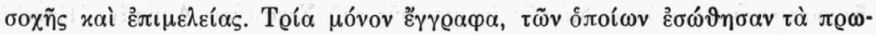

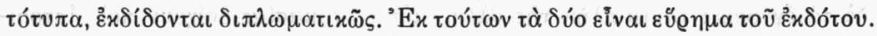

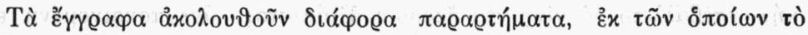

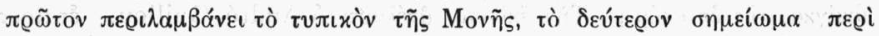

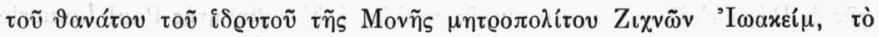

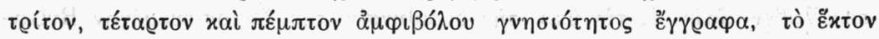

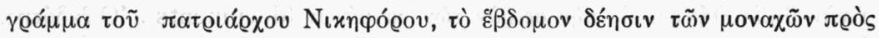

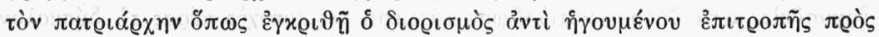

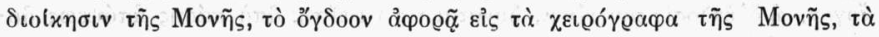

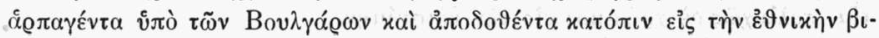

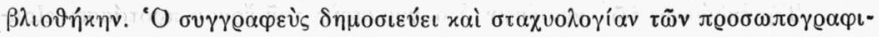

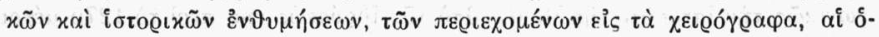

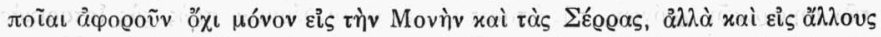

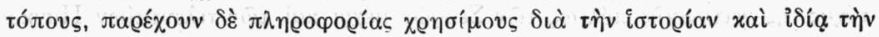

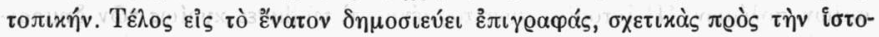

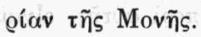

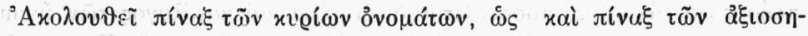

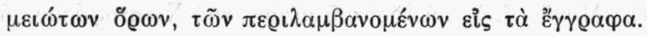

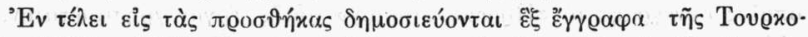

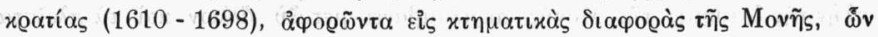

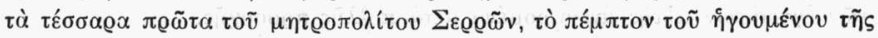

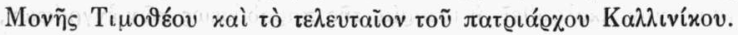

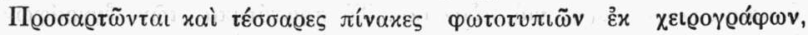

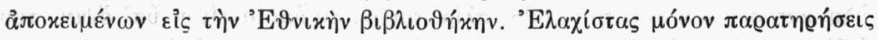

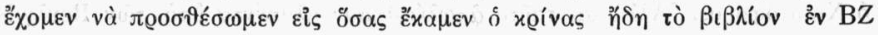
$(51,130)$ Dölger.

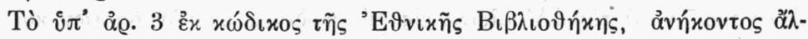

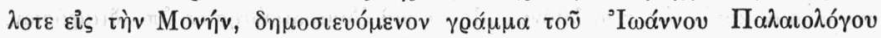

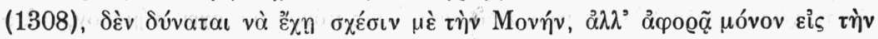

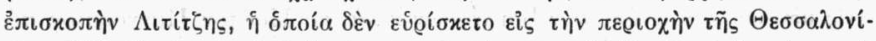

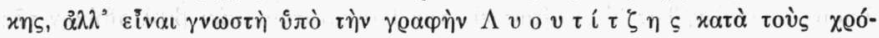

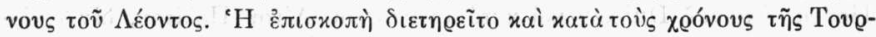

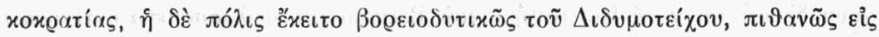

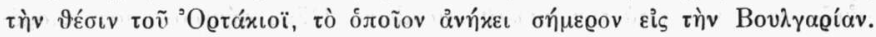

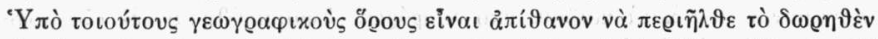

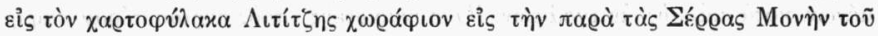

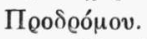

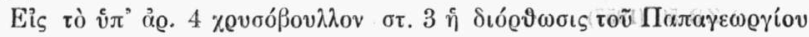




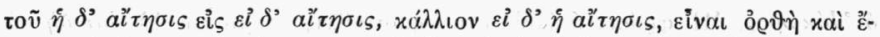

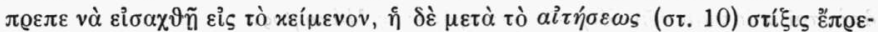

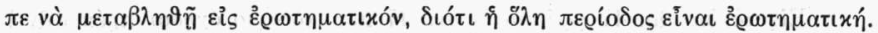

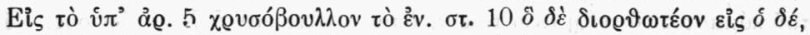

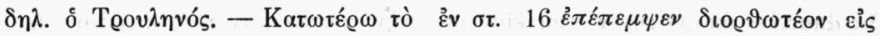

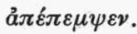

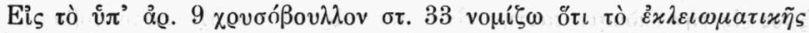

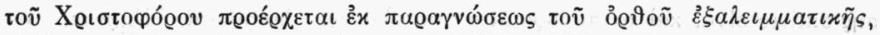

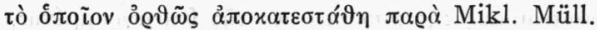

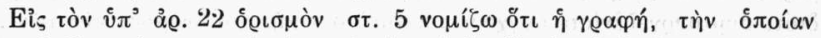

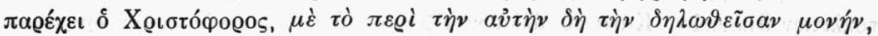

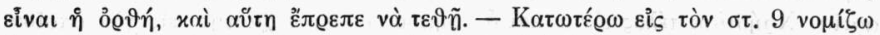

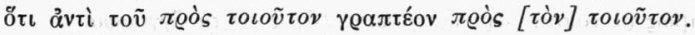

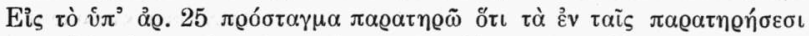

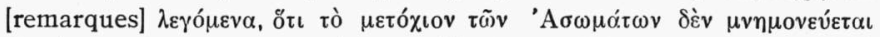

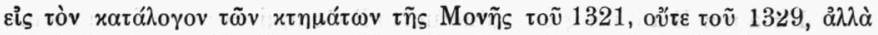

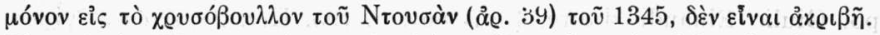

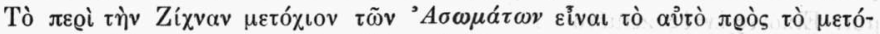

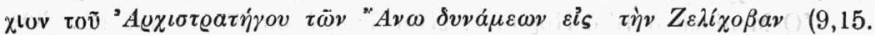

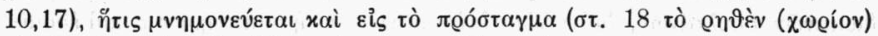

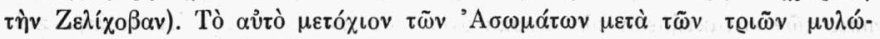

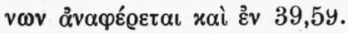

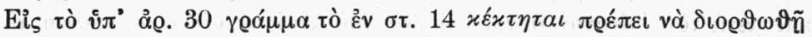

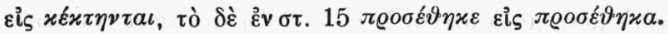

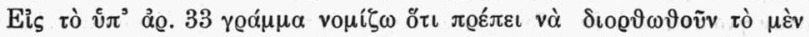

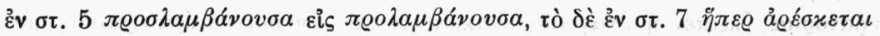

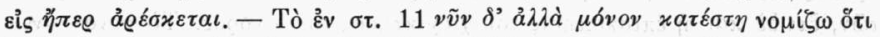

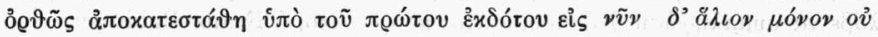

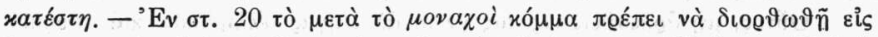

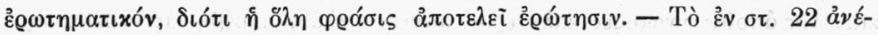

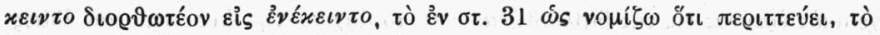

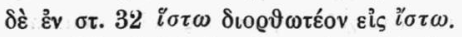

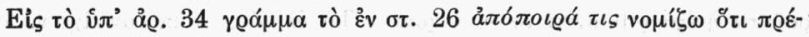

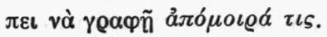

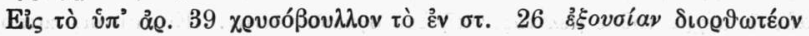

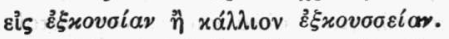

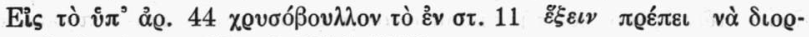

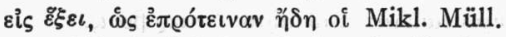

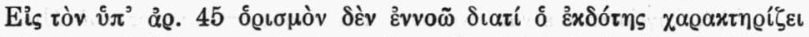

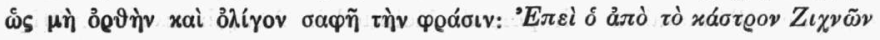




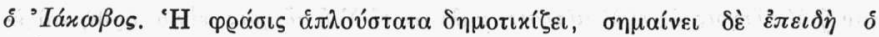

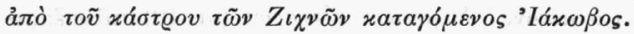

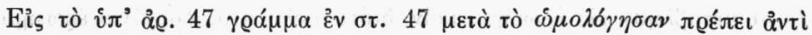

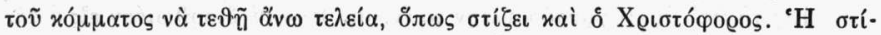
$\xi ı \varsigma$ ảं

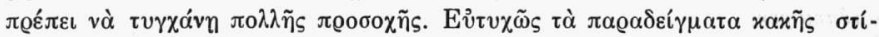

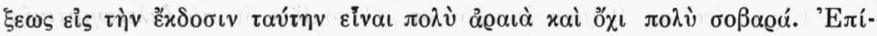

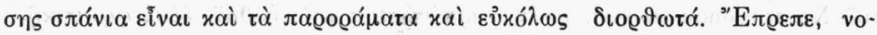

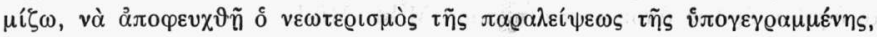

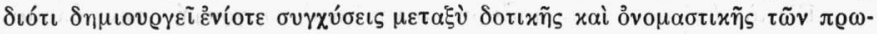

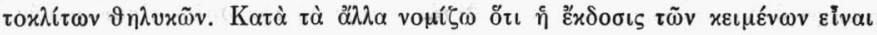

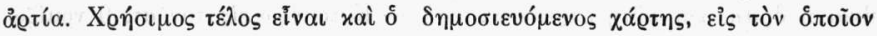

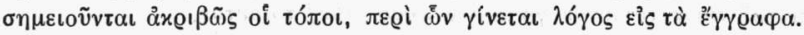

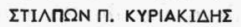

Fr a n z B a bi n g e r, Maometto il Conquistatore e il suo tem-

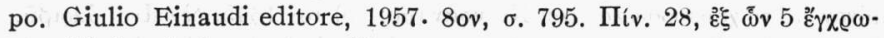

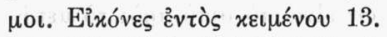

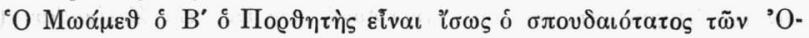

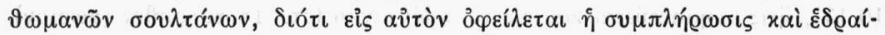

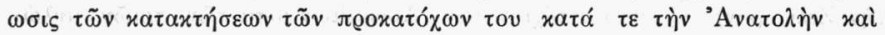

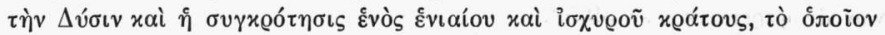

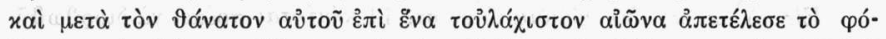

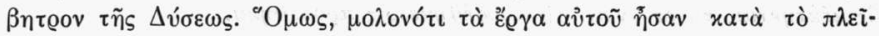

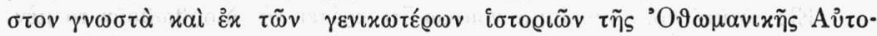

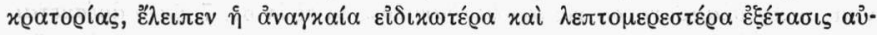

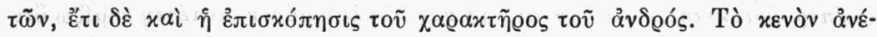

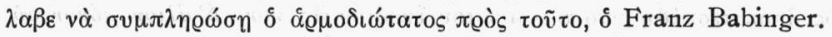

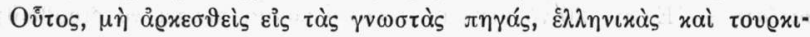

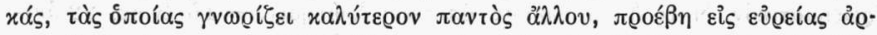

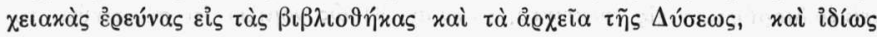

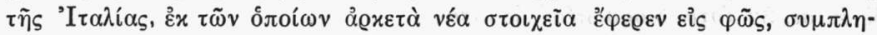

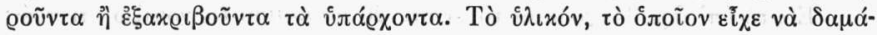

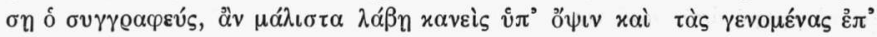

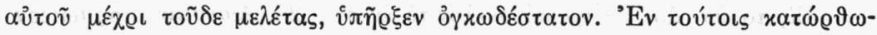

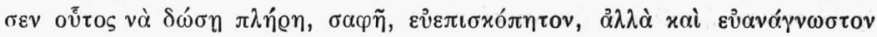

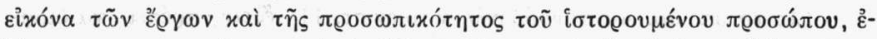

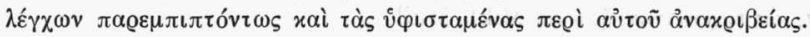

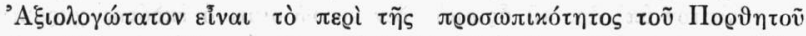

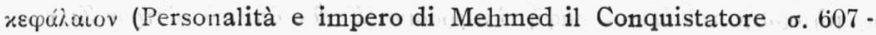

